\title{
PERSPECTIVE
}

\section{The lung and carbon dioxide: implications for permissive and therapeutic hypercapnia}

\author{
D.A. Kregenow, E.R. Swenson
}

\begin{abstract}
Although acute respiratory acidosis may be a sign of impending respiratory failure in spontaneously breathing patients, it is commonly encountered in intubated patients with acute lung injury (ALI). This is especially the case now that limiting tidal volumes and airway pressures have been proven to reduce mortality in ALI, presumably by reducing additional lung injury caused by mechanical ventilation itself [1]. A respiratory acidosis arising from lung-protective ventilation strategies has been termed permissive hypercapnia [2-5]. As the name indicates, permissive hypercapnia has been regarded as an inconvenient side-effect that must be tolerated in order to realise the mortality benefits of a low lung-stretch strategy.

There is growing evidence that hypercapnic acidosis may itself minimise or reduce lung injury as a result of suppressing inflammatory events. The mechanism(s) for this effect is (are) not entirely known. Nonetheless, there was sufficient suggestive data from cell culture and isolated organ studies over the past two decades for LAFFEY and KAVANAGH [6] not only to support the use of permissive hypercapnia but also to advocate the use of "therapeutic hypercapnia" through the addition of carbon dioxide $\left(\mathrm{CO}_{2}\right)$ to the inspired gas. In addition to the possibility of improved outcomes due to anti-inflammatory effects, hypercapnic acidosis has effects on ventilation-perfusion matching that improve gas exchange. Therapeutic hypercapnia has previously been shown to increase arterial oxygenation by this mechanism in normal animals [7, 8] and in a sheep model of Klebsiella pneumonia [9]. The only study of changes in gas exchange with permissive hypercapnia in humans with ALI showed an increase in shunt [10]. This was most likely due to a reduction in tidal volume used to produce a hypercapnic acidosis than to permissive hypercapnia itself. Thus, the effects of hypercapnic acidosis on ventilation, perfusion, and their regional matching in injured lungs remain largely unknown.
\end{abstract}

While the acute respiratory distress syndrome (ARDS) Network data have stated that physiological end-points such as gas exchange do not necessarily correlate with outcome, there are unanswered questions

Division of Pulmonary and Critical Care Medicine, University of Washington, Seattle, WA, USA.

Correspondence: E.R. Swenson, VA Puget Sound Health Care System, 1660 South Columbian Way, Box 358280 (S-111-PULM), Seattle, WA98108, USA. Fax: 1 2067642659. E-mail: eswenson@ u.washington.edu about the tolerable limits of hypoxaemia and acidosis which may influence clinical outcomes. With the growing acceptance of permissive hypercapnia in support of patients with lung injury on mechanical ventilation, studies such as that by NAOKI et al. [11] in this issue of the European Respiratory Journal, will be essential for a full understanding of the mechanisms by which hypercapnic acidosis affects gas exchange and inflammation. The authors have revealed an obviously complex system controlling microvascular tone that may differ between the normal and injured lung and may be heterogenous across various forms of lung injury. Their work adds to an already vast literature on $\mathrm{CO}_{2}$ and hydrogen ion $\left(\mathrm{H}^{+}\right)$effects on biochemical and physiological functions in the lung and other tissues. Importantly, they have begun to illuminate vascular events at the level of the microcirculation.

Using fluorescent confocal microscopy on the surface of isolated perfused rat lungs to measure microvessel diameter, NAOKI et al. [11] studied the responses to hypercapnic (respiratory) and isocapnic (metabolic) acidoses in normal lungs and those injured by hyperoxia. Research of this calibre has the potential to uncover new and little known interactions. For instance, they demonstrate complex associations between nitric oxide (NO), a molecule regarded primarily as a potent vasodilator, and cyclo-oxygenase $(\mathrm{COX})$, an enzyme generating both inflammatory and vasoactive eicosanoids such as prostaglandins, prostacyclin, and thromboxane. Specifically, they sought to determine the roles of $\mathrm{NO}$ and arachidonate metabolites, along with the responsible NO synthase (NOS) and cyclo-oxygenase isoforms, in controlling microvascular tone in the setting of respiratory and metabolic acidoses. The authors observations are both interesting and somewhat surprising. Hyperoxic lung injury leads to increased NO production by upregulation of endothelial cell NOS (ecNOS or NOS III). The importance of ecNOS induction was confirmed by the effects of nonselective NOS inhibition, lack of effect with selective inducible NOS (iNOS) inhibition, and Western blot analysis of lung homogenates. This is in contrast to other reports of lung injury in which iNOS is the isozyme usually induced by injury $[12,13]$. At the whole lung level, they found that $\mathrm{CO}_{2}$ and isocapnic acidosis caused a mild elevation in pulmonary artery pressure in normal lungs and that this pressure increase was doubled in hyperoxic lung injury. If it is assumed that left atrial pressure was 
unchanged, then this pressure change represents an increase in pulmonary vascular resistance because lung perfusate flow was constant. By clever use of combinations of NOS and COX isozyme inhibitors and NO donors, the authors established that upregulated endogenous NO production paradoxically contributes to hypercapnic (but not isocapnic) acidosis-associated vasodilation by the curious route of inhibiting COX-1 mediated formation of vasoconstricting prostaglandins in hyperoxic-injured lungs. However, when exogenous NO is provided in overwhelming amounts (with nitroprusside) then NO more classically acts as a direct vasodilator.

The measurements of acinar microvessel diameter revealed interesting and divergent responses, at the microvascular level, that would not be readily predicted by the changes in total pulmonary vascular resistance (PVR). As an example, the authors found that hypercapnic acidosis caused small venular dilation even in the face of increased resistance in upstream arterial resistance. To add to the complexity of understanding the effects of hypercapnia, they showed that small arterioles did not change with $\mathrm{CO}_{2}$, but unexpectedly dilated when ecNOS activity was inhibited. Furthermore, they found that this effect was blocked by COX-1 inhibition. The variety of findings they describe are not easily explained, but clearly the data reveal a complexity of PVR control and show how it may vary depending upon the exact circumstances, particularly in lung injury.

Although isolated perfused unventilated lungs, such as those highlighted by the authors, may be distinctly different from the in vivo activity of the lung, studies such as these are a necessary first step. While the acinar microvessels reveal several interesting results, it must be borne in mind that the arterioles and venules that play the dominant role in determining PVR and the distribution of pulmonary blood flow were not examined in this study. Nevertheless, the acinar microcirculation clearly does respond to both injury and agents that block or stimulate the production of vasoactive substances. Understanding the events that occur at the microvessels and capillaries is critical because they represent the largest surface area of the lung and it is here where oedema forms.

\section{Carbon dioxide and hydrogen ion chemistry}

When the large body of work on $\mathrm{CO}_{2}$ and acidosis is surveyed, the data, including that of NAOKI et al. [11], are not always consistent. $\mathrm{CO}_{2}$ and $\mathrm{pH}$ may act unpredictably and sometimes oppositely depending upon the experimental or clinical conditions. Generally, acidosis suppresses most cellular functions, and it is for this reason that the body uses a variety of strategies to defend its intra- and extracellular acidbase status within remarkably narrow limits [14-17]. The complexity in $\mathrm{CO}_{2}$ effects rests in the many ways that it directly and indirectly alters the extra- and intracellular milieu critical to "normal" functioning. The addition of $\mathrm{CO}_{2}$ leads to a greater $\mathrm{H}^{+}$concentration by its spontaneous and carbonic anhydrasecatalysed combination with water to form carbonic acid. The protons thus generated are free to react (or be buffered) with titratable groups in certain amino acids resulting in secondary and tertiary structural changes of many proteins and enzymes in cell membranes and cellular aqueous environments. In addition to its direct acidifying properties, $\mathrm{CO}_{2}$ can react with some free amine groups in proteins to form carbamate residues [18-20]. This binding of $\mathrm{CO}_{2}$ also modifies protein structure and function and may explain some of the differences observed in the effects of $\mathrm{CO}_{2}$ and $\mathrm{H}^{+}$when both lead to equal changes in $\mathrm{pH}$. The best example of the dual chemistry of $\mathrm{CO}_{2}$ and proteins is the well-known Bohr effect or lowering of haemoglobin-oxygen affinity. Given that these reactions can occur in almost any protein or enzyme, it should not be surprising that $\mathrm{CO}_{2}$ might act oppositely under different circumstances. One such example is the occasional study in which it is found that $\mathrm{CO}_{2}$ reduces pulmonary vascular resistance. How these $\mathrm{CO}_{2} / \mathrm{H}^{+}$-mediated perturbations in protein activity then alter cell processes is not fully known. They are likely to involve changes in membrane ion transport and electrochemical membrane potential, reductions in intracellular calcium concentration [21], alterations in microtubule assembly [19], decreases in enzyme activity and mediator synthesis, inhibition of apoptosis [22], and changes in gene transcription [23].

With regard to gene transcription, respiratory acidosis may act in ways different from the action of metabolic acidosis [24]. Rounds et al. [25] have shown that a variety of unidentified proteins are upregulated in the normal lung with hypercapnia. Analogous to the better known effects of hypoxia in altering gene transcription via hypoxia-inducible factor, there is very recent evidence for membrane acid-sensing ion channels and acid-responsive gene promotor regions $[24,26,27]$. How the more chronic use of hypercapnia in critically ill patients affects these acid sensing mechanisms and changes in gene transcription remains completely unexplored.

\section{Effects of hypercapnia on inflammation}

As discussed earlier, hypercapnia and other forms of acidosis have suppressive effects on inflammatory events. With reference to support of patients with lung injury and multi-organ failure, it has been shown that restoration of blood flow and/or oxygen delivery to a previously ischaemic and/or hypoxic tissue is less injurious if the reperfusing fluid is acidic. Thus, gradual rather than rapid restoration of intracellular $\mathrm{pH}$ while cells become re-oxygenated minimises the cellular injury associated with ischaemia-reperfusion. This effect has been labelled the "pH paradox" and was first described for the heart and liver [28-32], but subsequently has also been shown in lung, kidney and brain [33-38]. This paradigm led LAFFEY et al. [39] to take permissive hypercapnia one step further by deliberately adding $\mathrm{CO}_{2}$ to the ventilating gas of ischaemic lungs in vivo. Therapeutic hypercapnia markedly reduced the extent of ischaemia-reperfusion injury. Subsequent studies of this strategy have demonstrated reductions in ventilator-induced lung 
Table 1.-Immuno-modulatory and protective effects of acidosis

Inhibition of xanthine oxidase and oxygen radical formation Reduced neutrophil respiratory burst

Reduced leucocyte and vascular endothelial cell cytokine release

TNF- $\alpha$

IL-8

IL-6

Inhibition of neutrophil chemotaxis

Changes in cellular adhesion molecule expression

Inhibition of NO synthases

Impairment of phagocytosis

Decreased antibody synthesis

Increased complement activation

TNF: tumour necrosis factor; IL: interleukin; NO: nitric oxide.

injury in both isolated perfused lungs and recently in an in vivo animal model $[40,41]$.

Table 1 lists a number of possible $\mathrm{CO}_{2}$ and $\mathrm{pH}$ mediated anti-inflammatory mechanisms that may contribute to lung protection with therapeutic hypercapnia [6, 42, 43]. Some exceptions have been reported, in part due to antipodal effects of severe acidosis $(\mathrm{pH}<6.5)$ and those under more mild-tomoderate conditions $(\mathrm{pH}>6.8)$. One example is $\mathrm{NO}$ production that rises in conditions of severe acidosis but is often suppressed with mild acidosis [44 47]. Other critical factors include whether in vitro studies were performed in $\mathrm{CO}_{2}$-free artifical buffers or $\mathrm{CO}_{2} /$ bicarbonate $\left(\mathrm{HCO}_{3}^{-}\right)$buffered systems, and the specific cause of lung injury. It is obvious that acidosis is a two-edged sword that may prove difficult to wield in critically ill patients because infection or the risk of infection is always present. Indeed, this problem has plagued virtually all attempts to use selective and nonselective anti-inflammatory or immune modulating interventions in critical care [48-49].

\section{Effects of hypercapnia on systemic and pulmonary physiology}

If permissive or therapeutic hypercapnia is to be used rationally and safely in intensive care settings, there are a number of physiological effects, due to alterations in $\mathrm{pH}$ and the $\mathrm{CO}_{2}$ tension in arterial blood $\left(P \mathrm{a}, \mathrm{CO}_{2}\right)$, that need to be considered. While adding $\mathrm{CO}_{2}$ to the gas mixture of artificially ventilated patients who are often tachypnoeic may seem counterintuitive, there are likely to be select patient populations in whom the benefits of therapeutic hypercapnia may outweigh its risks and inconveniences. Tables 2 and 3 list many of the pulmonary and systemic effects of hypercapnic acidosis that have relevance in situations where therapeutic hypercapnia might be initiated. As is the case for the anti-inflammatory effects, the physician must be aware of the competing and sometimes compensatory nature of these actions.

In the lung, in contrast to the systemic circulation, there is usually constriction in the pulmonary vasculature in response to hypercapnic acidosis. The strength of hypercapnic vasoconstriction is generally
Table 2. - Systemic effects of hypercapnic acidosis

CNS

Ventilatory stimulation

General anaesthesia at high levels

Cerebral vasodilation

Increased intra-cranial pressure

Increased sympathetic tone

Decreased parasympathetic tone

Increased adrenal medullary and cortical output

Cardiovascular

Direct effects

Impaired contractility of cardiac and vascular smooth muscle

Reduced afterload and systemic vasodilation

Opposing consequence of heightened sympathetic tone Increased cardiac frequency

Increased myocardial contractility

Increased venous capacitance vessel tone

Increased venous return

Increased cardiac output

Metabolism

Reduced oxygen consumption

Altered cellular fuel utilisation

Increased cellular ketoacid and lactic acid uptake

Renal/electrolyte

Increased $\mathrm{H}^{+}$secretion and $\mathrm{HCO}_{3}$ reabsorption

Renal adrenergic-mediated vasoconstriction at high levels Increased $\mathrm{Na}^{+}$reabsorption

Mild hyperkalemia

Blood

Small increase in haematocrit/haemoglobin concentration

Reduced haemoglobin $\mathrm{O}_{2}$ affinity (increased p50)

Suppression of erythropoietin release

CNS: central nervous system; $\mathrm{H}^{+}$: hydrogen ion; $\mathrm{HCO}_{3}$ : bicarbonate; $\mathrm{Na}^{+}$: sodium; $\mathrm{O}_{2}$ : oxygen.

weaker than that of hypoxic pulmonary vasoconstriction (HPV) and its more important effect may be in augmenting HPV. While the membrane and cellular mechanisms of HPV are a focus of intense investigation, less is understood about how $\mathrm{CO}_{2}$ acts on pulmonary vascular smooth muscle. Analogous to $\mathrm{HPV}$, the effect may be a complex summation of changes in membrane potential, alterations in membrane potassium $\left(\mathrm{K}^{+}\right)$and calcium $\left(\mathrm{Ca}^{2+}\right)$ channel activity, and alterations in both vascular endothelial cell vasoconstrictor and vasodilator substances. For example, NAOKI et al. [11] demonstrated the interaction between $\mathrm{NO}$ and prostaglandins. The balance may not be the same in different portions of the pulmonary circulation, such that some segments of the vasculature may respond in an opposing manner to others. This was reported by NAOKI et al. [11] in their normal rats in which PVR rose but there was

\section{Table 3. - Pulmonary effects of hypercapnic acidosis}

Vagally mediated large airway constriction

Direct small airway dilation

Increased collateral ventilation

Improved surfactant function and increased secretion

Increased parenchymal compliance

Increased pulmonary vascular resistance

Enhanced hypoxic vasoconstriction

Improved $V^{\prime} / Q^{\prime}$ matching

$V^{\prime} / Q^{\prime}:$ ventilation/perfusion. 
venular dilation. In addition, the route by which $\mathrm{CO}_{2}$ is added to the lung (inhaled versus delivered by the vasculature) may evoke differing responses among arteries and veins [50]. Although NAOKI et al. [11] found no effect of hypercapnic or isocapnic acidosis on capillary diameters, the capillary bed and its surrounding parenchyma do possess contractile elements whose state of tone may be important in setting intercellular gap tensions, transvascular fluid flux, and alveolar-capillary permeability [51, 52].

The airways and lung parenchyma also respond to changing $\mathrm{CO}_{2}$ and $\mathrm{pH}$ as listed in table 3. Again a degree of heterogeneity of effects exists as exemplified by differences in behaviour between large and small airways [53]. The opposing balanced airway action of $\mathrm{CO}_{2}$ explains why global dynamic airway pressure measurements barely change with $\mathrm{CO}_{2}$ inhalation. Parenchymal compliance is sensitive to $\mathrm{CO}_{2}$ and in general increases in response to hypercapnic acidosis. This may be due to increased surfactant secretion and more effective surface tension-lowering properties under acidic conditions [54]. The combined effect of small-airway dilation with $\mathrm{CO}_{2}$ and increased compliance underlies the phenomenon of hypocapnic broncho- and pneumo-constriction observed with acute regional pulmonary artery occlusions [55, 56]. The vascular, airway, and compliance effects of $\mathrm{CO}_{2}$ are best considered as mechanisms that serve ventilation/perfusion $\left(V^{\prime} / Q^{\prime}\right)$ matching. They may either alter regional ventilation to keep pace with a primary change in perfusion, or alter regional perfusion to match a primary change in ventilation [57]. Very recently the current authors have shown that if the addition of inspired $\mathrm{CO}_{2}$ is limited to the latter portion of the inspirate, improved $V^{\prime} / Q^{\prime}$ matching occurs without systemic respiratory acidosis [58]. This suggests that therapeutic hypercapnia might be limited selectively to the lung.

The numerous systemic effects of $\mathrm{CO}_{2}$ present several clinically significant scenarios. Although hypercapnic acidosis reduces cardiac contractility in isolated hearts and vascular smooth muscle, the hypercapnic-mediated sympathoadrenal effects of increased preload, decreased afterload, and increased cardiac frequency lead to a net increase in cardiac output. It is against this background that one must be judicious with hypercapnia in any patient on $\beta$-adrenergic antagonists or those with heart failure or coronary artery disease. The increase in cerebral blood flow with hypercapnic acidosis must be considered carefully in any patient as a potential risk for raised intracranial pressure [59]. The marked sympathetic activation of hypercapnic acidosis, particularly when combined with arterial hypoxaemia, can lead to intense renal vasoconstriction (unlike elsewhere in the circulation) and avid tubular $\mathrm{Na}^{+}$reabsorption causing depressed glomerular filtration and increased fluid retention [60].

\section{Conclusion}

As permissive hypercapnia becomes more commonly accepted, tolerated, and practiced, the issues and physiology discussed in this perspective need to come into sharper focus and be better understood. It is hoped that permissive hypercapnia and therapeutic hypercapnia may offer real benefits, but only wellplanned and executed clinical studies will reveal the answer. Furthermore, as with any medication or intervention, the therapeutic index must be quantified and found to be safe enough for widespread use. Much work lies ahead.

\section{References}

1. The acute respiratory distress syndrome network. Ventilation with lower tidal volumes as compared with traditional tidal volumes for acute lung injury and the acute respiratory distress syndrome. $N$ Engl $J$ Med 2000; 342: 1301-1308.

2. Hickling KG, Walsh J, Henderson S, Jackson R. Low mortality rate in adult respiratory distress syndrome using low-volume, pressure-limited ventilation with permissive hypercapnia: A prospective study. Crit Care Med 1994; 22: 1568-1578.

3. Amato M, Barbas C, Medeiros D, et al. Beneficial effects of the "open lung approach" with low distending pressures in ARDS: A prospective randomized study on mechanical ventilation. Am J Respir Crit Care Med 1995; 152: 1835-1846.

4. Gentilello LM, Anardi D, Mock C, Arreola-Risa C, Maier RV. Permissive hypercapnia in trauma patients. J Trauma 1995; 39: 846-52; discussion 852-853.

5. Amato MB, Barbas CS, Medeiros DM, et al. Effect of a protective-ventilation strategy on mortality in the acute respiratory distress syndrome. $N$ Engl J Med 1998; 338: 347-354.

6. Laffey JG, Kavanagh BP. Carbon dioxide and the critically ill - too little of a good thing? Lancet 1999; 354: 1283-1286.

7. Domino KB, Swenson ER, Polissar NL, Lu Y, Eisenstein BL, Hlastala MP. Effect of inspired $\mathrm{CO}_{2}$ on ventilation and perfusion heterogeneity in hyperventilated dogs. J Appl Physiol 1993; 75: 1306-1314.

8. Swenson ER, Robertson HT, Hlastala MP. Effects of inspired carbon dioxide on ventilation-perfusion matching in normoxia, hypoxia, and hyperoxia. Am J Respir Crit Care Med 1994; 149: 1563-1569.

9. Keenan RJ, Todd TRJ, Demajo W, Slutsky AS. Effects of hypercarbia on arterial and alveolar oxygen tensions in a model of Gram-negative pneumonia. J Appl Physiol 1990; 68: 1820-1825.

10. Feihl F, Eckert P, Brimioulle S, et al. Permissive hypercapnia impairs pulmonary gas exchange in the acute respiratory distress syndrome. Am J Respir Crit Care Med 2000; 162: 209-215.

11. Naoki K, Kudo H, Suzuki K, et al. NOS and COX isoforms and abnormal microvessel responses to $\mathrm{CO}_{2}$ and $\mathrm{H}^{+}$in hyperoxia-injured lungs. Eur Respir J 2002; 20: 43-51.

12. Potter CF, Kuo NT, Farver CF, et al. Effects of hyperoxia on nitric oxide synthase expression, nitric oxide activity, and lung injury in rat pups. Pediatr Res 1999; 45: 8-13.

13. Okamoto I, Abe M, Shibata K, et al. Evaluating the role of inducible nitric oxide synthase using a novel and selective inducible nitric oxide synthase inhibitor in septic lung injury produced by cecal ligation 
and puncture. Am J Respir Crit Care Med 2000; 162: 716-722.

14. Lubman RL, Crandall ED. Regulation of intracellular pH in alveolar epithelial cells. Am J Physiol 1992; 262: L1-L14.

15. Smith GL, Austin C, Crichton C, Wray S. A review of the actions and control of intracellular $\mathrm{pH}$ in vascular smooth muscle. Cardiovasc Res 1998; 38: 316-331.

16. Swenson ER. Tissue and cellular carbon dioxide transport and acid-base balance. In: Haddad GG, Abman SH, Chernick V, eds. Basic mechanisms of pediatric respiratory disease. Hamilton, Ontario, BC Decker Inc., 2002; pp. 216-233.

17. Nilius B, Viana F, Droogmans G. Ion channels in vascular endothelium. Annu Rev Physiol 1997; 59: 145-170.

18. Gros G, Forster RE, Lin L. The carbamate reaction of glycylglycine, plasma, and tissue extracts evaluated by a pH stopped flow apparatus. J Biol Chem 1976; 251: 4398-4407.

19. Clark RW, Volpi M, Berlin RD. Carbamate formation on tubulin: $\mathrm{CO}_{2} /$ bicarbonate buffers protect tubulin from inactivation by reductive methylation and carbamoylation and promote microtubule assembly at alkaline pH. Biochemistry 1988; 27: 1025-1033.

20. Max B. This and that: The neurotoxicity of carbon dioxide. TIPS 1991; 12: 408-411.

21. Nishio K, Suzuki Y, Takeshita K, et al. Effects of hypercapnia and hypocapnia on $\left[\mathrm{Ca}^{2+}\right]_{\mathrm{i}}$ mobilization in human pulmonary artery endothelial cells. $J$ Appl Physiol 2001; 90: 2094-2100.

22. D'Arcangelo D, Facchiano F, Barlucchi LM, et al. Acidosis inhibits endothelial cell apoptosis and function and induces basic fibroblast growth factor and vascular endothelial growth factor expression. Circ Res 2000; 86: 312-318.

23. Somero GN. Protons, osmolytes, and fitness of internal milieu for protein function. Am $J$ Physiol 1986; 251: R197-R213.

24. Curthoys NP, Gstraunthaler G. Mechanism of increased renal gene expression during metabolic acidosis. Am J Physiol Renal Physiol 2001; 281: F381-F390.

25. Rounds S, Piggott D, Dawicki DD, Farber HW. Effect of hypercarbia on surface proteins of cultured bovine endothelial cells. Am J Physiol 1997; 273: L1141-L1146.

26. Bassler EL, Ngo-Anh TJ, Geisler HS, Ruppersberg JP, Grunder S. Molecular and functional characterization of acid-sensing ion channel (ASIC) 1B. J Biol Chem 2001; 276: 33782-33787.

27. Yiangou Y, Facer P, Smith JA, et al. Increased acidsensing ion channel ASIC-3 in inflamed human intestine. Eur J Gastroenterol Hepatol 2001; 13: 891896.

28. Kitakaze M, Weisfeldt ML, Marban E. Acidosis during early reperfusion prevents myocardial stunning in perfused ferret hearts. J Clin Invest 1988; 82: 920-927.

29. Currin RT, Gores GJ, Thurman RG, Lemasters JJ. Protection by acidotic $\mathrm{pH}$ against anoxic cell killing in perfused rat liver: evidence for a $\mathrm{pH}$ paradox. FASEB $J$ 1991; 5: 207-210.

30. Nomura F, Aoki M, Forbess JM, Mayer JE. Effects of hypercarbic acidotic reperfusion on recovery of myocardial function after cardioplegic ischemia in neonatal lambs. Circulation 1994; 90: II321-II327.
31. Caldwell-Kenkel JC, Currin RT, Coote A, Thurman RG, Lemasters JJ. Reperfusion injury to endothelial cells after cold storage of rat livers: protection by mildly acidic $\mathrm{pH}$ and lack of protection by antioxidants. Transpl Int 1995; 8: 77-85.

32. Hurtado $C$, Pierce GN. Inhibition of $\mathrm{Na}^{+} / \mathrm{H}^{+}$ exchange at the beginning of reperfusion is cardioprotective in isolated, beating adult cardiomyocytes. J Mol Cell Cardiol 2000; 32: 1897-1907.

33. D'Armini AM, Lemasters JJ, Egan TM, Vigano M. Effect of perfusion $\mathrm{pH}$ on rat lung viability on nonheart beating donors. Eur J Cardio-thoracic Surg 1997; 12: 787-791.

34. Moore TM, Khimenko PL, Taylor AE. Restoration of normal $\mathrm{pH}$ triggers ischemia-reperfusion injury in lung by $\mathrm{Na}^{+} / \mathrm{H}^{+}$exchange activation. Am J Physiol 1995; 269: H1501-H1505.

35. Sakuma T, Takahashi K, Ohya N, et al. Ischemiareperfusion lung injury in rabbits: Mechanisms of injury and protection. Am J Physiol 1999; 276: L137L145.

36. Zager RA, Schimpf BA, Gmur DJ. Physiological pH. Effects on posthypoxic proximal tubular injury. Circ Res 1993; 72: 837-846.

37. Martin LF, Peter AO, Fehr DM, Landis JR, Cotter J, Briggs RW. 31P-NMR evaluation of postischemia renal ATP and $\mathrm{pH}$ levels after ATP- $\mathrm{MgCl}_{2}$ treatment in rabbits. Am J Surg 1992; 164: 132-139.

38. Phillis JW, Estevez AY, Guyot LL, O'Regan MH. 5-(n-ethyl-n-isopropyl)-amiloride, an $\mathrm{Na}(+)-\mathrm{H}(+)$ exchange inhibitor, protects gerbil hippocampal neurons from ischemic injury. Brain Res 1999; 839: 199-202.

39. Laffey JG, Tanaka M, Engelberts D, et al. Therapeutic hypercapnia reduces pulmonary and systemic injury following in vivo lung reperfusion. Am J Respir Crit Care Med 2000; 162: 2287-2294.

40. Broccard A, Hotchkiss J, Vannay C, et al. Protective effects of hypercapnic acidosis on ventilator-induced lung injury. Am J Respir Crit Care Med 2001; 164: 802-806.

41. Sinclair SE, Kregenow DA, Lamm WJE, Starr IR, Chi EY, Hlastala MP. Hyperpcapnic acidosis is protective in an in vivo model of ventilator-induced lung injury. Am J Respir Crit Care Med 2002; (in press).

42. Shibata K, Cregg N, Engelberts D, Takeuchi A, Fedorko L, Kavanagh BP. Hypercapnic acidosis may attenuate acute lung injury by inhibition of endogenous xanthine oxidase. Am J Respir Crit Care Med 1998; 158: 1578-1584.

43. Lardner A. The effects of extracellular $\mathrm{pH}$ on immune function. J Leukoc Biol 2001; 69: 522-530.

44. Pedoto A, Caruso JE, Nandi J, et al. Acidosis stimulates nitric oxide production and lung damage in rats. Am J Respir Crit Care Med 1999; 159: $397-$ 402.

45. Brogan TV, Hedges RG, McKinney S, Robertson HT, Hlastala MP, Swenson ER. Pulmonary NO synthase inhibition and inspired $\mathrm{CO}_{2}$ : Effects on $V / Q$ and pulmonary blood flow distribution. Eur Respir J 2000; 16: 288-295.

46. Lang JDJ, Chumley P, Eiserich JP, et al. Hypercapnia induces injury to alveolar epithelial cells via a nitric oxide-dependent pathway. Am J Physiol 2000; 279: L994-L1002.

47. Yamamoto Y, Nakano H, Ide H, et al. Role of airway 
nitric oxide on the regulation of pulmonary circulation by carbon dioxide. J Appl Physiol 2001; 91: 1121-1130.

48. Lefering R, Neugebauer EA. Steroid controversy in sepsis and septic shock: a meta-analysis. Crit Care Med 1995; 23: 1294-1303.

49. Kox WJ, Volk T, Kox SN, Volk HD. Immunomodulatory therapies in sepsis. Intensive Care Med 2000; 26: S124-S128.

50. Hyde RW, Lawson WH, Forster RE. Influence of carbon dioxide on pulmonary vasculature. $J$ Appl Physiol 1964; 19: 734-744.

51. Haberkern CM, Bland RD. Effect of hypercapnia on net filtration of fluid in the lungs of awake newborn lambs. J Appl Physiol 1981; 51: 423-427.

52. Dudek SM, Garcia JG. Cytoskeletal regulation of pulmonary vascular permeability. J Appl Physiol 2001; 91: $1487-1500$.

53. Ingram RH Jr. Effects of airway versus arterial $\mathrm{CO}_{2}$ changes on lung mechanics in dogs. J Appl Physiol 1975; 38: 603-607.

54. Wildeboer-Venema F. The influences of temperature and humidity upon the isolated surfactant film of the dog. Respir Physiol 1980; 39: 63-71.
55. Swenson EW, Finley TN, Guzman SV. Unilateral hypoventilation in man during temporary occlusion of one pulmonary artery. J Clin Invest 1961; 40: $828-835$.

56. Swenson ER, Graham MM, Hlastala MP. Acetazolamide slows $\mathrm{V}_{\mathrm{A}} / \mathrm{Q}$ matching after changes in regional blood flow. J Appl Physiol 1995; 78: 13121318.

57. Swenson ER, Domino KB, Hlastala MP. Physiological effects of oxygen and carbon dioxide on $\mathrm{V}_{\mathrm{A}} / \mathrm{Q}$ heterogeneity. In: Hlastala MP, Robertson HT, eds. Complexity in structure and function of the lung. New York, Marcel Dekker, Inc., 1998; pp. 511-547.

58. Brogan TV, Robertson HT, Souders JE, Swenson ER. Carbon dioxide added to the latter half of inspiration improves $\mathrm{V}_{\mathrm{A}} / \mathrm{Q}$ matching without causing respiratory acidosis. FASEB J 2002; 16: A876.

59. Feihl F, Perret C. Permissive hypercapnia: How permissive should we be? Am J Respir Crit Care Med 1994; 150: 1722-1737.

60. DiBona GF, Kopp UC. Neural control of renal function. Physiol Rev 1997; 77: 75-197. 